\title{
Comprehensive Geriatric Assessment as a Versatile Tool to Enhance the Care of the Older Person Diagnosed with Cancer
}

\author{
Janine Overcash $^{1, * \mathbb{D}}$, Nikki Ford ${ }^{2}$, Elizabeth Kress ${ }^{2}$, Caitlin Ubbing ${ }^{2}$ and Nicole Williams ${ }^{2}$ \\ 1 The College of Nursing, The Ohio State University, 1585 Neil Ave, Newton Hall, Columbus, OH 43201, USA \\ 2 Stephanie Spielman Comprehensive Breast Center, The Ohio State University, 1145 Olentangy River Road, \\ Columbus, OH 43121, USA; Nikki.Ford@osumc.edu (N.F.); Eizabeth.Kress@osumc.edu (E.K.); \\ Caitlin.Ubbing@osumc.edu (C.U.); Nicole.Williams@osumc.edu (N.W.) \\ * Correspondence: Overcash.1@osu.edu
}

Received: 20 May 2019; Accepted: 20 June 2019; Published: 24 June 2019

check for updates

\begin{abstract}
The comprehensive geriatric assessment (CGA) is a versatile tool for the care of the older person diagnosed with cancer. The purpose of this article is to detail how a CGA can be tailored to Ambulatory Geriatric Oncology Programs (AGOPs) in academic cancer centers and to community oncology practices with varying levels of resources. The Society for International Oncology in Geriatrics (SIOG) recommends CGA as a foundation for treatment planning and decision-making for the older person receiving care for a malignancy. A CGA is often administered by a multidisciplinary team (MDT) composed of professionals who provide geriatric-focused cancer care. CGA can be used as a one-time consult for surgery, chemotherapy, or radiation therapy providers to predict treatment tolerance or as an ongoing part of patient care to manage malignant and non-malignant issues. Administrative support and proactive infrastructure planning to address scheduling, referrals, and provider communication are critical to the effectiveness of the CGA.
\end{abstract}

Keywords: comprehensive geriatric assessment; CGA; multidisciplinary team; senior adult; cancer

Caring for the older adult who is diagnosed with cancer can be a complex orchestration of managing existing comorbid conditions, cancer care, caregiver concerns, while maintaining quality of life [1-4]. Older people have unique healthcare needs compared to younger adults who may not have challenges regarding comorbidities [4-7], functional ability [8], transportation and social support [9]. Many academic and community cancer centers establish some type of multidisciplinary geriatric oncology program to meet the needs of the older person [10-15]. The central element associated with a geriatric oncology program is a comprehensive geriatric assessment (CGA). Despite the evidence showing the benefits of CGA, only $9 \%$ and $8 \%$ of Phase II and Phase III clinical trials use CGA [16]. Many healthcare settings do not use CGA also because of time constraints, availability of a multidisciplinary team, and lack of professionals trained in geriatrics/gerontology. Conducting a CGA is feasible in ambulatory geriatric oncology programs (AGOPs) $[10,17]$ including radiation therapy and surgical oncology [18-20]. There are strategies to reduce the time and resources often required to conduct a CGA. The purpose of this article is to illustrate how CGA can be used in different types of AGOPs and is a feasible option despite limited time and personnel. A review of the classic and current literature was conducted using the Ohio State University (OSU) Health Sciences Library (HSL) including PubMed and Cumulative Index to Nursing and Allied Health Literature (CINAHL) to support this article.

\section{Defining a Comprehensive Geriatric Assessment}

A CGA is a battery of screening tools necessary to uncover actual and potential limitations that can compromise cancer diagnosis and treatment [21]. The Society for International Oncology in 
Geriatrics (SIOG) recommends a CGA be administered to older patients who are receiving cancer care [22,23]. Benefits of a CGA are prolonged survival [24], prediction of those who may not benefit from treatment [25], prediction of mortality [26], of cancer treatment tolerance [27], of chemotherapy toxicities [28], of surgical complications [29], and aid in decision-making to help avoid over- and undertreatment of cancer [30]. The battery of screening tools is generally assembled to address common problems associated with aging; however, any number of valid and reliable clinical instruments can be included, depending on the resources. Some cancer centers may be able to conduct large-scale CGA with a robust multidisciplinary team (MDT), and others may limit assessment instruments and MDT members.

The comprehensive character of geriatric assessment allows clinicians to gain perspective beyond the traditional oncology-related history and physical exam [31]. A CGA can detect previously unidentified problems in approximately $70 \%$ of patients [32], which can impact cancer treatment [19] and provide the foundation for a treatment plan to address malignant and nonmalignant conditions [33]. CGA is used to develop and refine a cancer management plan specific to the needs of the person diagnosed with cancer [20]. A prime goal of geriatric oncology is helping an older person achieve the best health possible while receiving cancer care to maintain independence [4].

\section{Instruments Included in a Comprehensive Geriatric Assessment}

Generally, screening tools to detect depression [34], comorbidity [35], cognitive impairment [36], functional status [37,38], risk for falls [39], and nutritional status [40] are commonly included in a CGA. The CGA is multidimensional in that many types of screening instruments can be included to meet the needs of people who are diagnosed with cancer or who are receiving end-of-life care [41], caregivers [42], and providers [43]. SIOG recommends a variety of instruments that can be tailored to any patient population [44].

When choosing instruments to include in a CGA, consider that there are performance-based evaluations and self-report measures. Performance-based evaluations provide a depiction of a person's capability using tools such as the Timed Up and Go Test (TUAGT) [45], balance testing [46], grip strength [47], sit-to-stand test [48], cognitive screening using the Clock Drawing Test [49], and other empirically measured tests. Self-report measures are also commonly included in the CGA, such as the Geriatric Depression Scale (GDS) [34], Activities of Daily Living Scale [37], Instrumental Activities of Daily Living [38], quality-of-life measures [50], and nutritional assessment [40]. Self-report measures tend to be rather easy to use and have validity and reliability metrics for clinical and research use. Including both self-report and performance-based evaluations provides patient perception of functioning at home in conjunction with an objective assessment. Some patients may tend to over-estimate their functional ability, and the empirical observation of task performance may help providers develop realistic management plans.

Supporting the caregiver is also important to the health of the person with cancer [51]. The Modified Caregiver Strain Index [52,53] is a 13-item tool that measures the financial, psychological, personal, physical, and social domains of caregiving which can be incorporated into a CGA. Caregivers of people diagnosed with cancer who have functional impairment [54] and have increased comorbidity [55] report greater strain and burden. CGA can stratify people with cancer into levels of caregiver burden risk so that clinicians can recognize caregivers who may need help [42]. Caregivers of people with advanced cancer often neglect their own health and wellness and report high levels of depression and anxiety [56]. Depression is not rare among caregivers (42\%), and clinicians must support and encourage health maintenance and wellness [57]. If caregiver health is not maintained and perceptions of strain and burden exist, the individual with cancer is at risk for re-hospitalization [58] and increased morbidity/mortality [59]. Help for caregivers navigating community resources, Medicare, insurance, and cancer treatment can be very welcomed [60]. Cancer can be overwhelming and expensive, and providing psychosocial support can reduce caregiver stress associated with financial toxicity [61], 
address depression, and establish coping strategies [62]. No matter the scale of the CGA, caregiver support is important to geriatric oncology.

\section{Multidisciplinary Team}

A MDT has historically been used in geriatrics to administer the CGA and manage the many interwoven concerns that can affect older people $[63,64]$. An MDT can be composed of physicians, social workers, pharmacists, nurses, nurse practitioners, dietitians, physical therapists, and other types of healthcare professionals. Not every clinic may have access to a variety of specialists, and it is important to remember that geriatric care and screening can be provided by physicians, nurse practitioners, and nurses. An MDT may simply include a physician and a nurse who are trained in geriatrics. Administering and coordinating a CGA is well within the scope of practice of nursing and can be central to the effectiveness of the MDT [65].

Whatever the size, an MDT functions symbiotically to assess, manage, and monitor many limitations and complications associated with aging and deconditioning [66]. Geriatric oncology has adopted the MDT approach to improve or maintain independence [67] and to provide CGA by which to impact the cancer management plan [20]. Key to an effective MDT are communication, collaboration, and coordination [68]. A social worker, nurse practitioner, and dietitian can evaluate a patient simultaneously and hear the responses from individual assessments, so that questions are not duplicated. This method requires a cohesive teamwork, does save some time, and enhances communication within the MDT. An MDT with a perception of cohesive teamwork provides higher quality of care and less attrition in the nursing staff [69]. Communication with primary care providers and other specialists is critical to geriatric oncology and successful interventions [70]. When primary care providers and oncology providers agree on recommendations, adherence to CGA recommendations is more likely to occur [71].

For providers who lack a MDT, nurse-conducted CGA is a viable option. Nurses and/or advanced practice nurses often function in the role of coordinator, provider, communicator, and organizer. Awareness of the current knowledge in normative aging, geriatric syndromes, wellness, and prevention are components of nursing best practices [72]. Best practices in geriatric/gerontological competencies are provided by the American Association of Colleges of Nursing (AACN) for advanced practice and baccalaureate nurses and largely guide curriculum development for colleges of nursing throughout the United States [73,74]. However, geriatric training is often lacking in nursing schools throughout the country [75], and geriatric education is often received outside of the academic curriculum. The National Hartford Center of Gerontological Nursing Excellence (NHCGNE) aims to enhance gerontological education among nurses in the academic and clinical workforce [76]. The NHCGNE recognizes gerontological nurse educators as Distinguished Educators in Gerontological Nursing Program for working with faculty to enhance university and college curricula, educate nursing students at all levels, and work with other providers to better care for the older person [77]. It is important that nurses are educated in gerontology/geriatrics so they are prepared to assess and contribute to the care of the older person who is diagnosed with cancer [78].

\section{Management of Problems Detected by Comprehensive Geriatric Assessment}

Geriatric syndromes (poor functional status, cognitive impairment, frailty), life expectancy, and comorbidity are realities that oncology providers must consider when caring for older individuals. The mean number of geriatric syndromes is 2.9 in community-dwelling older people [79] and when uncontrolled, may interfere with cancer treatment. Complex problems associated with geriatric syndromes often cannot be addressed in one clinic visit or with a single medication or intervention. For frailer people, determining the cause of a problem may require an MDT-administered CGA and several clinic visits to detect and manage complex problems [80]. Good general health and absence of severe comorbidity allow older people to be considered for surgical [81] and other types of standard treatments [82]. 
People who have well-managed comorbidities may not have any deterioration in their functional status or life expectancy. In non-metastatic prostate cancer patients receiving treatment, 10-year life expectancy was not impacted by comorbid conditions nor age [83]. However, data show that for every chronic condition, life expectancy decreases 1.8 years [61]. Life expectancy, comorbid conditions, and functional status are sentinel factors in geriatric oncology [84]. Functional status and not chronological age is an important consideration in cancer treatment planning for the older adult [28,85].

Initiating a CGA requires a process to manage the limitations uncovered by the evaluation, and providers should be trained on how to incorporate the MDT recommendations in the decision-making process [86]. The mean number of CGA recommendations to address the uncovered limitations ranges from seven [87] to two [88], depending on the type of patient (frail, vulnerable, or fit) [89]. A CGA performed upon an initial oncology encounter can render three interventions [90]. Patients are most likely to adhere to four or less recommendations unless they present cognitive decline, in which case adherence is lower [87].

Follow-up care is important to determine adherence to recommendations and to reassess the issues that were previously detected [91]. The problems detected in the CGA should be managed or referred and detailed in the medical record [92,93]. How often to administer the CGA depends on the degree of fitness or frailty of the patient. A primary care nurse who is trained in geriatrics can be effective in coordinating the recommendations [94].

\section{Comprehensive Geriatric Assessment with Limited Resources}

A CGA conducted by an MDT can require an hour or more to administer; however, there are strategies to conduct CGA in a timely and efficient manner. Targeting the person who would most likely benefit from the CGA with a prescreening instrument can help preserve the resources of clinical time and personnel and reduce the respondent burden (Figure 1).

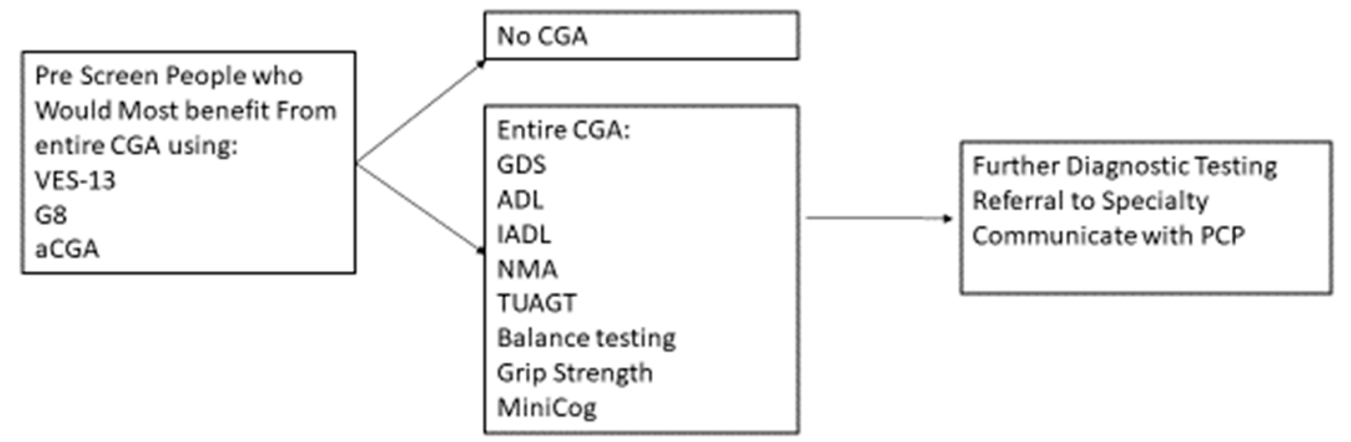

Figure 1. Prescreening using CGA to Determine Further Treatment or Diagnostics.

Prescreens have been developed, such as the abbreviated CGA [95], the G8 [96], and the Vulnerable Elders Survey-13 [97]. SIOG recommends several valid and reliable pre-screen tools [1]. The purpose of pre-screen tools is to target those who most benefit from conducting the entire CGA, rather than to replace a CGA. People who have functional decline and a higher risk of mortality and of cancer treatment complications tend to benefit from the CGA [98,99]. For those people who are independent and with minimal comorbid conditions, a CGA may not be as beneficial [100].

Depending on resources and type of healthcare setting, a CGA can be fashioned to include only several instruments rather than an exhaustive battery of tools requiring hours of clinic encounter time. Creating a smaller version of CGA which can include two or three screening instruments (GDS, Mini-Cog, TUAGT) will allow time to gain experience administering the instrument and managing the limitations. Using only two or three screening instruments has reasonable benefit to people who are diagnosed with cancer and to their families. The detection and management of depression can contribute to better cancer treatment outcomes, particularly with adherence to recommendations [101]. Benefits of screening for cognitive limitations are inconclusive [102]; however, other considerations 
such as planning, awareness of limitations, preparation for future and other important tasks can be very helpful for patients and families. Screening using the TUAGT can lead to physical therapy consults [88] to enhance lower extremity strength and to provide falls education and proactive planning should a fall occur (determining how to get help, keeping a phone on the bathroom floor near the bathing area). The use of three tools can provide the opportunity to address common problems that can be associated with aging without requiring the time to conduct a more robust CGA (Figure 2).

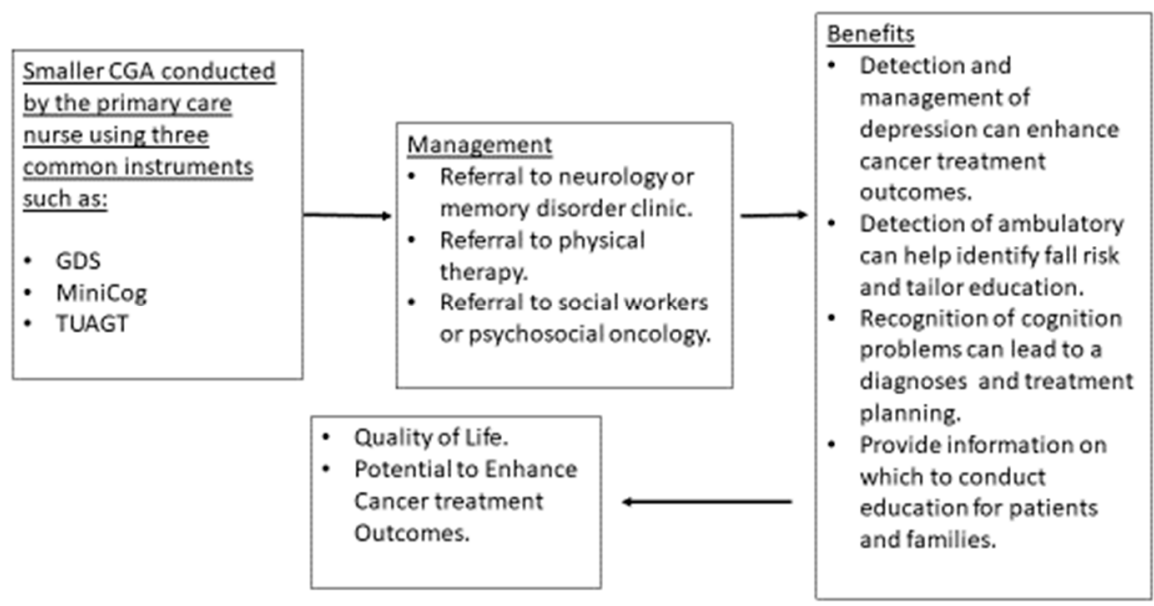

Figure 2. Smaller CGA to Determine Further Treatment or Diagnostics.

The use of pre-screens and a smaller battery of assessment instruments is a viable option when using CGA with limited clinical resources. Understanding the versatility of CGA may motivate more clinicians to employ best practices in geriatric assessment.

Cost and resources are a factor when establishing a geriatric oncology program; however, not all data indicate that CGA is cost-prohibitive when looking at long-term expenses and hospital stay. The SIOG suggests that CGA is cost-effective and reduces hospitalizations [103]. CGA in people who experience a hip fracture reduces hospital costs and hospital length of stay and improves health outcomes [104]. However, for those people admitted to the hospital for nonmalignant conditions, CGA is thought to slightly increase costs [105]. A Swedish study found ambulatory oncology CGA to have increased costs due to the number of interventions and increased survival [25]. Another Swedish study found ambulatory CGA to increase survival in frail people, with fewer hospital days and without higher costs [106]. In the United States, the cost savings or expenses may be different, however, people tend to benefit from CGA $[85,107]$.

\section{Models of Geriatric Oncology Programs Using CGA}

AGOPs often include regular CGAs and manage a patient throughout cancer care. There are different types of AGOPs, such as those that provide ongoing geriatric oncology management, one-time consult programs, site specific programs, and programs that address patients according to age and not a particular tumor type. Scale also varies among AGOPs, with some using large MDTs and others consisting of an oncologist and a geriatric trained nurse. Regardless of the structure, AGOPs can provide CGA and offer management strategies to enhance the care of the older person diagnosed with cancer.

The CGA can be administered by a nurse or nurse practitioner, and scores on the measures can be shared with the entire MDT, so that more in-depth screening can be conducted by the appropriate specialists. In some situations, the MDT members individually screen new patients to establish a baseline condition prior to cancer treatment. The MDT members can then evaluate the patient as needed throughout cancer treatment. Established patients who have received a baseline CGA can receive regular geriatric assessment screening every 6 months or every year. No data exist on how 
often to conduct a CGA; however, frail or vulnerable patients may require more frequent screening. The National Comprehensive Cancer Network (NCCN) has established guidelines for using CGA when caring for the older adult [108]. A pre-cancer treatment decision tree addresses how and when to use a prescreening and an entire CGA and how CGA can impact treatment decisions for the patient, family, and provider [108].

Scheduling new and established patients visits for any type of AGOP requires planning for extra time to conduct the CGA. For AGOPs conducting the entire CGA with an MDT in addition to establishing a cancer management plan, a new patient visit may require two hours. For those AGOPs using limited measures in the CGA and a limited MDT, perhaps a 30 min visit is appropriate. One-time CGA consults can be easier to schedule in that all patients tend to receive the same screening instruments and assessment from the MDT. Generally, the consult can be conducted in approximately 1.5 to $2 \mathrm{~h}$ per patient. Depending on the physical environment of the clinic, three patients can be scheduled every 2-2.5 hour and be accommodated with rotating members of the team conducting the assessments.

An AGOP one-time CGA consult functions to provide recommendations for cancer treatment, identifies comorbid conditions, and addresses actual and potential risk factors that can affect health and independence. A one-time CGA consult can be helpful to surgical teams to predict complications [109] and post-surgical delirium when administered prior to surgery [110]. A one-time CGA conducted by a geriatrician prior to emergency surgery reduces hospital length of stay by 55 days [111]. Despite the positive contributions of CGA, many surgeons and other providers fail to consult geriatric services [112]. Education on the benefits of CGA in cancer treatment decision-making is critical for all cancer specialties and providers.

Conducting a CGA and incorporating an MDT require infrastructures and administrative support to lay the foundation for a sustainable geriatric oncology. Often, facilities and providers have difficulty launching and maintaining senior adult programs, for many reasons [113]. Patient scheduling to accommodate longer visit times [114], avenues of referral when limitations are found, adapting the medical record to accommodate scores and recommendations are important tasks to address before initiating geriatric assessment [13]. AGOPs require continued evaluation and maintenance to ensure the process of clinic is working well and the MDT is functioning effectively and productively. Regular team meetings can be helpful to discuss assessment process, patients, and research activities. Regular meetings should include administration, office staff who schedule patient visits, as well as people who work with medical records, who can be helpful in establishing highly functioning clinics, especially in big medical centers. MDT meetings prior to geriatric oncology clinic are very useful to review new and established patients.

A prime component of infrastructure is communication with other providers, which is key to the effectiveness of AGOPs. Many providers feel under-utilized in the development of cancer management plans, and communication is often poor between oncologists and primary care providers [94]. Proactive planning to establish avenues of communication to coordinate the CGA recommendations can reduce redundant assessments and increase effectiveness. Follow-up care and adherence to recommendations are likely to be improved with better communication between geriatric MDTs and other providers and typically require organizational modifications for adequate transfer of patient information [115].

Patient referral to an AGOP is also a consideration when establishing a clinic or a process for other oncology providers to refer patients for a one-time CGA consult or ongoing management. Awareness of the AGOP should be created within the organization and the community. Often, community members are not aware of geriatric oncology services, and providing educational symposiums or brief presentations at various sites common to potential patients and families can offer the opportunity to receive a CGA and cancer care.

An AGOP can provide valuable clinical data to enhance the care of the older person diagnosed with cancer. Establishing a research protocol incorporating CGA data can help improve the science of geriatric oncology and establish a foundation for future funding. Select CGA instruments can be 
useful clinically as well as appropriate for research. Dissemination is critical to geriatric oncology and helps address the importance of CGA in the care of the older person diagnosed with cancer.

\section{Conclusions}

CGA is a versatile tool that can be integrated into various oncology clinics and specialties to provide the best care for the older person. Integrating a CGA does require administrative support, infrastructure for patient scheduling, MDT involvement, and a great deal of planning. The importance of understanding the needs of older people with cancer and of their caregivers underscores the significance of CGA and inspires a comprehensive view, helpful to make treatment decisions. CGA is the central element of geriatric oncology and the gold standard of practice to meet the needs of older people.

Author Contributions: Individual contributions are as follows: conceptualization, writing original—draft preparation, writing- review and editing draft preparation was performed by J.O., conceptualization writing —review and editing draft preparation was completed by E.K., N.F., C.U. and N.W.

Funding: This research received no external funding.

Acknowledgments: We would like to thank the Stephanie Spielman Comprehensive Breast Cancer for continued support of geriatric oncology and our Senior Adult Oncology Program.

Conflicts of Interest: We have no conflicts of interest to declare.

\section{References}

1. Rocque, G.; Azuero, A.; Halilova, K.; Williams, C.; Kenzik, K.; Yagnik, S.K.; Pisu, M. Most Impactful Factors on the Health-Related Quality of Life of a Geriatric Population with Cancer (S769). J. Pain Symptom Manag. 2018, 55, 694-695. [CrossRef]

2. Hurria, A. Management of Elderly Patients With Cancer. J. Natl. Compr. Cancer Netw. 2013, 11, 698-701. [CrossRef]

3. Vallet-Regí, M.; Manzano, M.; López, M.C.; Aapro, M.; Barbacid, M.; Guise, T.A.; Balducci, L.; Mena, A.C.; Romero, P.L.O.; Orellana, M.R.; et al. Management of Cancer in the Older Age Person: An Approach to Complex Medical Decisions. Oncol. 2017, 22, 335-342. [CrossRef] [PubMed]

4. Balducci, L. Treatment of Breast Cancer in Women Older Than 80 Years Is a Complex Task. J. Oncol. Pr. 2016, 12, 133-134. [CrossRef] [PubMed]

5. Williams, G.R.; Deal, A.M.; Lund, J.L.; Chang, Y.; Muss, H.B.; Pergolotti, M.; Guerard, E.J.; Shachar, S.S.; Wang, Y.; Kenzik, K.; et al. Patient-Reported Comorbidity and Survival in Older Adults with Cancer. Oncologist 2018, 23, 433-439. [CrossRef]

6. Klepin, H.D.; Pitcher, B.N.; Ballman, K.V.; Kornblith, A.B.; Hurria, A.; Winer, E.P.; Hudis, C.; Cohen, H.J.; Muss, H.B.; Kimmick, G.G.; et al. Comorbidity, Chemotherapy Toxicity, and Outcomes Among Older Women Receiving Adjuvant Chemotherapy for Breast Cancer on a Clinical Trial: CALGB 49907 and CALGB 361004 (Alliance). J. Oncol. Pr. 2014, 10, e285-e292. [CrossRef] [PubMed]

7. Kim, K.H.; Lee, J.J.; Kim, J.; Zhou, J.-M.; Gomes, F.; Sehovic, M.; Extermann, M. Association of multidimensional comorbidities with survival, toxicity, and unplanned hospitalizations in older adults with metastatic colorectal cancer treated with chemotherapy. J. Geriatr. Oncol. 2019. [CrossRef]

8. Mariano, C.; Williams, G.; Deal, A.; Alston, S.; Bryant, A.L.; Jolly, T.; Muss, H.B. Geriatric Assessment of Older Adults With Cancer During Unplanned Hospitalizations: An Opportunity in Disguise. Oncol. 2015, 20, 767-772. [CrossRef]

9. Tjong, M.C.; Menjak, I.; Trudeau, M.; Mehta, R.; Wright, F.; Leahey, A.; Ellis, J.; Gallagher, D.; Gibson, L.; Bristow, B.; et al. Perceptions and Expectations of Older Women in the Establishment of the Senior Women's Breast Cancer Clinic (SWBCC): A Needs Assessment Study. J. Cancer Educ. 2017, 32, 850-857. [CrossRef]

10. Magnuson, A.; Dale, W.; Mohile, S. Models of Care in Geriatric Oncology. Curr. Geriatr. Rep. 2014, 3, $182-189$. [CrossRef]

11. O'Donovan, A.; Leech, M.; Mohile, S. Expert consensus panel guidelines on geriatric assessment in oncology. Eur. J. Cancer Care 2015, 24, 574-589. [CrossRef] [PubMed] 
12. Burhenn, P.S.; Perrin, S.; McCarthy, A.L.; Information, P.E.K.F.C. Models of Care in Geriatric Oncology Nursing. Semin. Oncol. Nurs. 2016, 32, 24-32. [CrossRef] [PubMed]

13. Overcash, J. Integrating Geriatrics Into Oncology Ambulatory Care Clinics. Clin. J. Oncol. Nurs. 2015, 19, E80-E86. [CrossRef] [PubMed]

14. Goede, V.; Stauder, R. Multidisciplinary care in the hematology clinic: Implementation of geriatric oncology. J. Geriatr. Oncol. 2018, 10, 497-503. [CrossRef] [PubMed]

15. Chapman, A.E.; Swartz, K.; Schoppe, J.; Arenson, C. Development of a comprehensive multidisciplinary geriatric oncology center, the Thomas Jefferson University Experience. J. Geriatr. Oncol. 2014, 5, 164-170. [CrossRef]

16. Le Saux, O.; Falandry, C.; Gan, H.K.; You, B.; Freyer, G.; Péron, J. Changes in the Use of Comprehensive Geriatric Assessment in Clinical Trials for Older Patients with Cancer over Time. Oncol. 2019. [CrossRef] [PubMed]

17. Puts, M.T.E.; Hardt, J.; Monette, J.; Girre, V.; Springall, E.; Alibhai, S.M.H. Use of Geriatric Assessment for Older Adults in the Oncology Setting: A Systematic Review. J. Natl. Cancer Inst. 2012, 104, 1134-1164. [CrossRef] [PubMed]

18. Szumacher, E.; Sattar, S.; Neve, M.; Do, K.; Ayala, A.; Gray, M.; Lee, J.; Alibhai, S.; Puts, M. Use of Comprehensive Geriatric Assessment and Geriatric Screening for Older Adults in the Radiation Oncology Setting: A Systematic Review. Clin. Oncol. 2018, 30, 578-588. [CrossRef]

19. Alibhai, S.M.; Jin, R.; Loucks, A.; Yokom, D.W.; Watt, S.; Puts, M.; Timilshina, N.; Berger, A. Beyond the black box of geriatric assessment: Understanding enhancements to care by the geriatric oncology clinic. J. Geriatr. Oncol. 2018, 9, 679-682. [CrossRef]

20. Festen, S.; Kok, M.; Hopstaken, J.S.; van der Wal-Huisman, H.; van der Leest, A.; Reyners, A.K.L.; de Bock, G.H.; de Graeff, P.; van Leeuwen, B.L. How to incorporate geriatric assessment in clinical decision-making for older patients with cancer. An implementation study. J. Geriatr. Oncol. 2019. [CrossRef]

21. Solomon, D. National Institutes of Health Consensus Development Conference Statement: Geriatric Assessment Methods for Clinical Decision-Making. Am. Geriatr. Soc. 1988, 36, 342-437.

22. Wildiers, H.; Heeren, P.; Puts, M.; Topinkova, E.; Janssen-Heijnen, M.L.; Extermann, M.; Falandry, C.; Artz, A.; Brain, E.; Colloca, G.; et al. International Society of Geriatric Oncology Consensus on Geriatric Assessment in Older Patients With Cancer. J. Clin. Oncol. 2014, 32, 2595-2603. [CrossRef] [PubMed]

23. Mohile, S.G.; Velarde, C.; Hurria, A.; Magnuson, A.; Lowenstein, L.; Pandya, C.; O'Donovan, A.; Gorawara-Bhat, R.; Dale, W. Geriatric Assessment-Guided Care Processes for Older Adults: A Delphi Consensus of Geriatric Oncology Experts. J. Natl. Compr. Cancer Netw. 2015, 13, 1120-1130. [CrossRef]

24. Kenis, C.; Baitar, A.; DeCoster, L.; De Grève, J.; Lobelle, J.-P.; Flamaing, J.; Milisen, K.; Wildiers, H. The added value of geriatric screening and assessment for predicting overall survival in older patients with cancer. Cancer 2018, 124, 3753-3763. [CrossRef] [PubMed]

25. Lundqvist, M.; Alwin, J.; Henriksson, M.; Husberg, M.; Carlsson, P.; Ekdahl, A.W. Cost-effectiveness of comprehensive geriatric assessment at an ambulatory geriatric unit based on the AGe-FIT trial. BMC Geriatr. 2018, 18, 32. [CrossRef] [PubMed]

26. Hamaker, M.E.; Vos, A.G.; Smorenburg, C.H.; De Rooij, S.E.; Van Munster, B.C. The Value of Geriatric Assessments in Predicting Treatment Tolerance and All-Cause Mortality in Older Patients With Cancer. Oncol. 2012, 17, 1439-1449. [CrossRef] [PubMed]

27. Freyer, G.; Geay, J.-F.; Touzet, S.; Provencal, J.; Weber, B.; Jacquin, J.-P.; Ganem, G.; Mathieu, N.T.; Gisserot, O.; Pujade-Lauraine, E. Comprehensive geriatric assessment predicts tolerance to chemotherapy and survival in elderly patients with advanced ovarian carcinoma: A GINECO study. Ann. Oncol. 2005, 16, 1795-1800. [CrossRef] [PubMed]

28. Soto-Perez-De-Celis, E.; Li, D.; Yuan, Y.; Lau, Y.M.; Hurria, A. Functional versus chronological age: Geriatric assessments to guide decision making in older patients with cancer. Lancet Oncol. 2018, 19, e305-e316. [CrossRef]

29. Kristjansson, S.R.; Nesbakken, A.; Jordhøy, M.S.; Skovlund, E.; Audisio, R.A.; Johannessen, H.-O.; Bakka, A.; Wyller, T.B. Comprehensive geriatric assessment can predict complications in elderly patients after elective surgery for colorectal cancer: A prospective observational cohort study. Crit. Rev. Oncol. 2010, 76, 208-217. [CrossRef] 
30. Schiphorst, A.H.; Ten Bokkel Huinink, D.; Breumelhof, R.; Burgmans, J.P.; Pronk, A.; Hamaker, M.E. Geriatric consultation can aid in complex treatment decisions for elderly cancer patients. Eur. J. Cancer Care (Engl.) 2016, 25, 365-370. [CrossRef]

31. Caillet, P.; Laurent, M.; Bastuji-Garin, S.; Liuu, E.; Culine, S.; Lagrange, J.-L.; Canoui-Poitrine, F.; Paillaud, E. Optimal management of elderly cancer patients: Usefulness of the Comprehensive Geriatric Assessment. Clin. Interv. Aging 2014, 9, 1645-1660. [PubMed]

32. Horgan, A.M.; Leighl, N.B.; Coate, L.; Liu, G.; Palepu, P.; Knox, J.J.; Perera, N.; Emami, M.; Alibhai, S.M. Impact and feasibility of a comprehensive geriatric assessment in the oncology setting: A pilot study. Am. J. Clin. Oncol. 2012, 35, 322-328. [CrossRef] [PubMed]

33. Hamaker, M.E.; Molder, M.T.; Thielen, N.; Van Munster, B.C.; Schiphorst, A.H.; Van Huis, L.H. The effect of a geriatric evaluation on treatment decisions and outcome for older cancer patients - A systematic review. J. Geriatr. Oncol. 2018, 9, 430-440. [CrossRef] [PubMed]

34. Yesavage, J.A.; Brink, T.; Rose, T.L.; Lum, O.; Huang, V.; Adey, M.; Leirer, V.O. Development and validation of a geriatric depression screening scale: A preliminary report. J. Psychiatr. Res. 1982, 17, 37-49. [CrossRef]

35. Charlson, M.E.; Pompei, P.; Ales, K.L.; MacKenzie, C. A new method of classifying prognostic comorbidity in longitudinal studies: Development and validation. J. Chronic Dis. 1987, 40, 373-383. [CrossRef]

36. Borson, S.; Scanlan, J.; Brush, M.; Vitaliano, P.; Dokmak, A. The Mini-Cog: A cognitive "vital signs" measure for dementia screening in multi-lingual elderly. Int. J. Geriatr. Psychiatry 2000, 15, 1021-1027. [CrossRef]

37. Katz, S.; Grotz, R.C.; Downs, T.D.; Cash, H.R. Progress in Development of the Index of ADL. Gerontol. 1970, 10, 20-30. [CrossRef] [PubMed]

38. Lawton, M.P.; Brody, E.M. Assessment of Older People: Self-Maintaining and Instrumental Activities of Daily Living. Gerontol. 1969, 9, 179-186. [CrossRef]

39. Kellogg International Work Group. A report of the Kellogg International Work Group on the Prevention of Falls by the Elderly. Dan. Med. Bull. 1987, 34 (Suppl. 4), 1-24.

40. Vellas, B.; Guigoz, Y.; Garry, P.J.; Nourhashemi, F.; Bennahum, D.; Lauque, S.; Albarède, J.-L. The mini nutritional assessment (MNA) and its use in grading the nutritional state of elderly patients. Nutr. 1999, 15, 116-122. [CrossRef]

41. Baronner, A.; MacKenzie, A. Using Geriatric Assessment Strategies to Lead End-of-Life Care Discussions. Curr. Oncol. Rep. 2017, 19. [CrossRef] [PubMed]

42. Rajasekaran, T.; Tan, T.; Ong, W.S.; Koo, K.N.; Chan, L.; Poon, D.; Chowdhury, A.R.; Krishna, L.; Kanesvaran, R.; Information, P.E.K.F.C. Comprehensive Geriatric Assessment (CGA) based risk factors for increased caregiver burden among elderly Asian patients with cancer. J. Geriatr. Oncol. 2016, 7, 211-218. [CrossRef] [PubMed]

43. Hamaker, M.; Seynaeve, C.; Wymenga, A.; Van Tinteren, H.; Nortier, J.; Maartense, E.; De Graaf, H.; De Jongh, F.; Braun, J.; Los, M.; et al. Baseline comprehensive geriatric assessment is associated with toxicity and survival in elderly metastatic breast cancer patients receiving single-agent chemotherapy: Results from the OMEGA study of the Dutch Breast Cancer Trialists' Group. Breast 2014, 23, 81-87. [CrossRef] [PubMed]

44. International Society of Oncology Geraitrics. Comprehensive Geraitric Assessment of the Older Person with Cancer. 2015. Available online: http://www.siog.org/content/comprehensive-geriatric-assessment-cga-olderpatient-cancer (accessed on 11 June 2019).

45. Podsiadlo, D.; Richardson, S. The Timed "Up \& Go": A Test of Basic Functional Mobility for Frail Elderly Persons. J. Am. Geriatr. Soc. 1991, 39, 142-148. [PubMed]

46. Berg, K.O.; Wood-Dauphinee, S.L.; Williams, J.I.; Maki, B. Measuring balance in the elderly: Validation of an instrument. Can. J. Public Heal. 1992, 83, S7-S11.

47. Mathiowetz, V.; Weber, K.; Volland, G.; Kashman, N. Reliability and validity of grip and pinch strength evaluations. J. Hand Surg. 1984, 9, 222-226. [CrossRef]

48. Jones, C.J.; Rikli, R.E.; Beam, W.C. A 30-s Chair-Stand Test as a Measure of Lower Body Strength in Community-Residing Older Adults. Res. Q. Exerc. Sport 1999, 70, 113-119. [CrossRef]

49. Borson, S.; Brush, M.; Gil, E.; Scanlan, J.; Vitaliano, P.; Chen, J.; Cashman, J.; Maria, M.M.S.; Barnhart, R.; Roques, J. The Clock Drawing Test: Utility for Dementia Detection in Multiethnic Elders. Journals Gerontol. Ser. A: Boil. Sci. Med Sci. 1999, 54, M534-M540. [CrossRef]

50. Cella, D.F.; Tulsky, D.S.; Gray, G.; Sarafian, B.; Linn, E.; Bonomi, A.; Silberman, M.; Yellen, S.B.; Winicour, P.; Brannon, J. The Functional Assessment of Cancer Therapy scale: Development and validation of the general measure. J. Clin. Oncol. 1993, 11, 570-579. [CrossRef] 
51. Sakurai, R.; Kawai, H.; Suzuki, H.; Kim, H.; Watanabe, Y.; Hirano, H.; Ihara, K.; Obuchi, S.; Fujiwara, Y. Poor Social Network, Not Living Alone, Is Associated With Incidence of Adverse Health Outcomes in Older Adults. J. Am. Med Dir. Assoc. 2019. [CrossRef]

52. Thornton, M.; Travis, S.S. Analysis of the Reliability of the Modified Caregiver Strain Index. Journals Gerontol. Ser. B 2003, 58, S127-S132. [CrossRef] [PubMed]

53. Robinson, B.C. Validation of a Caregiver Strain Index. J. Gerontol. 1983, 38, 344-348. [CrossRef] [PubMed]

54. Bień-Barkowska, K.; Doroszkiewicz, H.; Bień, B. Silent strain of caregiving: Exploring the best predictors of distress in family carers of geriatric patients. Clin. Interv. Aging 2017, 12, 263-274. [CrossRef] [PubMed]

55. Dauphinot, V.; Ravier, A.; Novais, T.; Delphin-Combe, F.; Moutet, C.; Xie, J.; Mouchoux, C.; Krolak-Salmon, P.; Information, P.E.K.F.C. Relationship Between Comorbidities in Patients With Cognitive Complaint and Caregiver Burden: A Cross-Sectional Study. J. Am. Med Dir. Assoc. 2016, 17, 232-237. [CrossRef]

56. Dionne-Odom, J.N.; Demark-Wahnefried, W.; Taylor, R.A.; Rocque, G.B.; Azuero, A.; Acemgil, A.; Martin, M.Y.; Astin, M.; Ejem, D.; Kvale, E.; et al. The Self-Care Practices of Family Caregivers of Persons with Poor Prognosis Cancer: Differences by Varying Levels of Caregiver Well-being and Preparedness. Support. Care Cancer 2017, 25, 2437-2444. [CrossRef] [PubMed]

57. Geng, H.M.; Chuang, D.M.; Yang, F.; Yang, Y.; Liu, W.M.; Liu, L.H.; Tian, H.M. Prevalence and determinants of depression in caregivers of cancer patients: A systematic review and meta-analysis. Medicine (Baltimore) 2018, 97, e11863. [CrossRef]

58. Bonin-Guillaume, S.; Durand, A.-C.; Yahi, F.; Curiel-Berruyer, M.; Lacroix, O.; Cretel, E.; Alazia, M.; Sambuc, R.; Gentile, S. Predictive factors for early unplanned rehospitalization of older adults after an ED visit: Role of the caregiver burden. Aging Clin. Exp. Res. 2015, 27, 883-891. [CrossRef] [PubMed]

59. Aggarwal, B.; Liao, M.; Christian, A.; Mosca, L. Influence of caregiving on lifestyle and psychosocial risk factors among family members of patients hospitalized with cardiovascular disease. J. Gen. Intern. Med. 2009, 24, 93-98. [CrossRef]

60. Lawn, S.; Westwood, T.; Jordans, S.; O'Connor, J. Support workers as agents for health behavior change: An Australian study of the perceptions of clients with complex needs, support workers, and care coordinators. Gerontol. Geriatr. Educ. 2017, 38, 496-516. [CrossRef]

61. DuGoff, E.H.; Canudas-Romo, V.; Buttorff, C.; Leff, B.; Anderson, G.F. Multiple chronic conditions and life expectancy: A life table analysis. Med. Care 2014, 52, 688-694. [CrossRef]

62. Nelson, C.J.; Saracino, R.M.; Roth, A.J.; Harvey, E.; Martin, A.; Moore, M.; Marcone, D.; Poppito, S.R.; Holland, J. Cancer and Aging: Reflections for Elders (CARE): A pilot randomized controlled trial of a psychotherapy intervention for older adults with cancer. Psychooncology 2019, 28, 39-47. [CrossRef] [PubMed]

63. Rubenstein, L.Z.; Josephson, K.R.; Wieland, G.D.; English, P.A.; Sayre, J.A.; Kane, R.L. Effectiveness of a Geriatric Evaluation Unit. New Engl. J. Med. 1984, 311, 1664-1670. [CrossRef] [PubMed]

64. Warren, M.W. Care of Chronic Sick. Br. Med. J. 1943, 2, 822-823. [CrossRef] [PubMed]

65. Trotta, R.L.; Rao, A.D.; Hermann, R.M.; Boltz, M.P. Development of a Comprehensive Geriatric Assessment Led by Geriatric Nurse Consultants: A Feasibility Study. J. Gerontol. Nurs. 2018, 44, 25-34. [CrossRef] [PubMed]

66. Flood, K.L.; Booth, K.; Vickers, J.; Simmons, E.; James, D.H.; Biswal, S.; Deaver, J.; White, M.L.; Bowman, E.H. Acute Care for Elders (ACE) Team Model of Care: A Clinical Overview. Geriatr. 2018, 3, 50. [CrossRef] [PubMed]

67. Balducci, L.; Yates, J. General guidelines for the management of older patients with cancer. Oncol. (Williston Park. N.Y.) 2000, 14, 221-227.

68. Karnakis, T.; Gattas-Vernaglia, I.F.; Saraiva, M.D.; Gil-Junior, L.A.; Kanaji, A.L.; Jacob-Filho, W. The geriatrician's perspective on practical aspects of the multidisciplinary care of older adults with cancer. J. Geriatr. Oncol. 2016, 7, 341-345. [CrossRef] [PubMed]

69. Piers, R.D.; Versluys, K.; Devoghel, J.; Vyt, A.; Noortgate, N.V.D. Interprofessional teamwork, quality of care and turnover intention in geriatric care: A cross-sectional study in 55 acute geriatric units. Int. J. Nurs. Stud. 2019, 91, 94-100. [CrossRef]

70. Nazir, A.; Unroe, K.; Tegeler, M.; Khan, B.; Azar, J.; Boustani, M. Systematic Review of Interdisciplinary Interventions in Nursing Homes. J. Am. Med Dir. Assoc. 2013, 14, 471-478. [CrossRef] 
71. Maly, R.C.; Leake, B.; Frank, J.C.; DiMatteo, M.R.; Reuben, D.B. Implementation of consultative geriatric recommendations: The role of patient-primary care physician concordance. J. Am. Geriatr. Soc. 2002, 50, 1372-1380. [CrossRef]

72. McConnell, E.S.; Lekan, D.; Bunn, M.; Egerton, E.; Corazzini, K.N.; Hendrix, C.D.; E Bailey, D. Teaching evidence-based nursing practice in geriatric care settings: The geriatric nursing innovations through education institute. J. Gerontol. Nurs. 2009, 35, 26-33. [PubMed]

73. American Assocaition of Colleges of Nursing. Adult Gerontology Acute Care and Primary Care Competencies. 2016. Available online: http://www.aacnnursing.org/Portals/42/AcademicNursing/pdf/Adult-Gero-NPComp-2016.pdf (accessed on 20 June 2019).

74. American Nurses Credentialing Center. Gerontological Nursing Certification. 2018. Available online: https://www.nursingworld.org/our-certifications/gerontological-nurse/ (accessed on 20 June 2019).

75. Gilje, F.; Lacey, L.; Moore, C. Gerontology and Geriatric Issues and Trends in U.S. Nursing Programs: A National Survey. J. Prof. Nurs. 2007, 23, 21-29. [CrossRef] [PubMed]

76. Bednash, G.; Mezey, M.; Tagliareni, E. The Hartford Geriatric Nursing Initiative experience in geriatric nursing education: Looking back, looking forward. Nurs. Outlook 2011, 59, 228-235. [CrossRef] [PubMed]

77. National Hartford Center of Nursing Excellence. Distinguished Educator in Gerontological Nursing. 2018. Available online: https:/www.nhcgne.org/leadership-development/distinguished-educator-ingerontological-nursing-program (accessed on 18 May 2019).

78. Burhenn, P.S.; McCarthy, A.L.; Begue, A.; Nightingale, G.; Cheng, K.; Kenis, C. Geriatric assessment in daily oncology practice for nurses and allied health care professionals: Opinion paper of the Nursing and Allied Health Interest Group of the International Society of Geriatric Oncology (SIOG). J. Geriatr. Oncol. 2016, 7, 315-324. [CrossRef] [PubMed]

79. Tkacheva, O.N.; Runikhina, N.K.; Ostapenko, V.S.; Sharashkina, N.V.; A Mkhitaryan, E.; Onuchina, J.S.; Lysenkov, S.N.; Yakhno, N.N.; Press, Y. Prevalence of geriatric syndromes among people aged 65 years and older at four community clinics in Moscow. Clin. Interv. Aging 2018, 13, 251-259. [CrossRef] [PubMed]

80. Overcash, J.; Cope, D.G.; Van Cleave, J.H. Frailty in Older Adults: Assessment, Support, and Treatment Implications in Patients With Cancer. Clin. J. Oncol. Nurs. 2018, 22, 8-18.

81. Banysch, M.; Akkaya, T.; Gurenko, P.; Papadakis, M.; Heuer, T.; Kasim, E.; Tavarajah, S.S.; Kaiser, G.M. Surgery for colorectal cancer in elderly patients: Is there such a thing as being too old? G Chir 2018, 39, 355-362.

82. Vitale, S.G.; Capriglione, S.; Zito, G.; Lopez, S.; Gulino, F.A.; Di Guardo, F.; Vitagliano, A.; Noventa, M.; La Rosa, V.L.; Sapia, F.; et al. Management of endometrial, ovarian and cervical cancer in the elderly: Current approach to a challenging condition. Arch. Gynecol. Obstet. 2019, 299, 299-315. [CrossRef]

83. Boehm, K.; Dell'Oglio, P.; Tian, Z.; Capitanio, U.; Chun, F.K.H.; Tilki, D.; Haferkamp, A.; Saad, F.; Montorsi, F.; Graefen, M.; et al. Comorbidity and age cannot explain variation in life expectancy associated with treatment of non-metastatic prostate cancer. World J. Urol. 2017, 35, 1031-1036. [CrossRef]

84. Shachar, S.S.; Hurria, A.; Muss, H.B. Breast Cancer in Women Older Than 80 Years. J. Oncol. Pr. 2016, 12, 123-132. [CrossRef]

85. Droz, J.-P.; Boyle, H.; Albrand, G.; Mottet, N.; Puts, M. Role of Geriatric Oncologists in Optimizing Care of Urological Oncology Patients. Eur. Urol. Focus 2017, 3, 385-394. [CrossRef] [PubMed]

86. Sarrió, R.G.; On behalf of the Spanish Working Group on Geriatric Oncology of the Spanish Society of Medical Oncology (SEOM); Rebollo, M.A.; Garrido, M.J.M.; Guillen-Ponce, C.; Blanco, R.; Flores, E.G.; Saldaña, J. General recommendations paper on the management of older patients with cancer: The SEOM geriatric oncology task force's position statement. Clin. Transl. Oncol. 2018, 20, 1246-1251.

87. Morin, T.; Lanièce, I.; Desbois, A.; Amiard, S.; Gavazzi, G.; Couturier, P. Evaluation of adherence to recommendations within 3 months after comprehensive geriatric assessment by an inpatient geriatric consultation team. Geriatr Psychol Neuropsychiatr Vieil 2012, 10, 285-293. [PubMed]

88. Overcash, J. Comprehensive Geriatric Assessment: Interprofessional Team Recommendations for Older Adult Women With Breast Cancer. Clin. J. Oncol. Nurs. 2018, 22, 304-315. [CrossRef] [PubMed]

89. Balducci, L. Frailty: A Common Pathway in Aging and Cancer. Primate Reproductive Aging 2013, 38, 61-72.

90. Boulahssass, R.; Gonfrier, S.; Champigny, N.; Lassalle, S.; François, E.; Hofman, P.; Guerin, O. The Desire to Better Understand Older Adults with Solid Tumors to Improve Management: Assessment and Guided Interventions-The French PACA EST Cohort Experience. Cancers 2019, 11, 192. [CrossRef] [PubMed] 
91. Extermann, M.; Aapro, M.; Bernabei, R.; Cohen, H.J.; Droz, J.P.; Lichtman, S.; Topinkova, E. Use of comprehensive geriatric assessment in older cancer patients: Recommendations from the task force on CGA of the International Society of Geriatric Oncology (SIOG). Crit. Rev. Oncol. Hematol. 2005, 55, 241-252. [CrossRef]

92. Mohile, S.G.; Dale, W.; Somerfield, M.R.; Schonberg, M.A.; Boyd, C.M.; Burhenn, P.S.; Canin, B.; Cohen, H.J.; Holmes, H.M.; Hopkins, J.O.; et al. Practical Assessment and Management of Vulnerabilities in Older Patients Receiving Chemotherapy: ASCO Guideline for Geriatric Oncology. J. Clin. Oncol. 2018, 36, 2326-2347. [CrossRef]

93. Verweij, N.M.; Souwer, E.T.D.; Schiphorst, A.H.W.; Maas, H.A.; Portielje, J.E.A.; Pronk, A.; Bos, F.V.D.; Hamaker, M.E. The effect of a geriatric evaluation on treatment decisions for older patients with colorectal cancer. Int. J. Color. Dis. 2017, 32, 1625-1629. [CrossRef]

94. Puts, M.T.; Strohschein, F.J.; Del Giudice, M.E.; Jin, R.; Loucks, A.; Ayala, A.P.; Alibhai, S.H. Role of the geriatrician, primary care practitioner, nurses, and collaboration with oncologists during cancer treatment delivery for older adults: A narrative review of the literature. J. Geriatr. Oncol. 2018, 9, 398-404. [CrossRef]

95. Overcash, J.A.; Beckstead, J.; Extermann, M.; Cobb, S. The abbreviated comprehensive geriatric assessment (aCGA): A retrospective analysis. Crit. Rev. Oncol. 2005, 54, 129-136. [CrossRef]

96. Soubeyran, P.-L.; Bellera, C.; Goyard, J.; Heitz, D.; Curé, H.; Rousselot, H.; Albrand, G.; Servent, V.; Jean, O.S.; Van Praagh, I.; et al. Screening for Vulnerability in Older Cancer Patients: The ONCODAGE Prospective Multicenter Cohort Study. PLOS ONE 2014, 9, 115060. [CrossRef] [PubMed]

97. Mohile, S.G.; Bylow, K.; Dale, W.; Dignam, J.; Martin, K.; Petrylak, D.P.; Stadler, W.M.; Rodin, M. A pilot study of the vulnerable elders survey-13 compared with the comprehensive geriatric assessment for identifying disability in older patients with prostate cancer who receive androgen ablation. Cancer 2007, 109, 802-810. [CrossRef] [PubMed]

98. Torres, C.H.; Hsu, T. Comprehensive Geriatric Assessment in the Older Adult with Cancer: A Review. Eur. Urol. Focus 2017, 3, 330-339. [CrossRef] [PubMed]

99. Locher, C.; Pourel, N.; Le Caer, H.; Bérard, H.; Auliac, J.-B.; Monnet, I.; Descourt, R.; Vergnenègre, A.; Lafay, I.M.; Greillier, L.; et al. Impact of a comprehensive geriatric assessment to manage elderly patients with locally advanced non-small-cell lung cancers: An open phase II study using concurrent cisplatin-oral vinorelbine and radiotherapy (GFPC 08-06). Lung Cancer 2018, 121, 25-29. [CrossRef]

100. Palmer, K.; Onder, G. Comprehensive geriatric assessment: Benefits and limitations. Eur. J. Intern. Med. 2018, 54, e8-e9. [CrossRef] [PubMed]

101. Decker, V.; Sikorskii, A.; Given, C.W.; Given, B.A.; Vachon, E.; Krauss, J.C. Effects of depressive symptomatology on cancer-related symptoms during oral oncolytic treatment. Psychooncology 2019, 28, 99-106. [CrossRef]

102. Moyer, V.A.; Force, U.P.S.T. Screening for cognitive impairment in older adults: U.S. Preventive Services Task Force recommendation statement. Ann. Intern. Med. 2014, 160, 791-797. [CrossRef]

103. Extermann, M. Geriatric Assessment with Focus on Instrument Selectivity for Outcomes. Cancer J. 2005, 11, 474-480. [CrossRef]

104. Eamer, G.; Saravana-Bawan, B.; Van Der Westhuizen, B.; Chambers, T.; Ohinmaa, A.; Khadaroo, R.G. Economic evaluations of comprehensive geriatric assessment in surgical patients: A systematic review. J. Surg. Res. 2017, 218, 9-17. [CrossRef]

105. Gardner, M.; Tsiachristas, A.; Langhorne, P.; Burke, O.; Harwood, R.H.; Conroy, S.P.; Kircher, T.; Somme, D.; Saltvedt, I.; Wald, H.; et al. Comprehensive geriatric assessment for older adults admitted to hospital. Cochrane Database Syst. Rev. 2017, 2017, CD006211.

106. Ekdahl, A.W.; Alwin, J.; Eckerblad, J.; Husberg, M.; Jaarsma, T.; Mazya, A.L.; Milberg, A.; Krevers, B.; Unosson, M.; Wiklund, R.; et al. Long-Term Evaluation of the Ambulatory Geriatric Assessment: A Frailty Intervention Trial (AGe-FIT): Clinical Outcomes and Total Costs After 36 Months. J. Am. Med. Dir. Assoc. 2016, 17, 263-268. [CrossRef] [PubMed]

107. Bhatt, V.R. Personalizing therapy for older adults with acute myeloid leukemia: Role of geriatric assessment and genetic profiling. Cancer Treat. Rev. 2019, 75, 52-61. [CrossRef]

108. NCCN. Clinical Practice Guidelines in Oncology: Older Adult Oncology; NCCN: Plymouth Meeting, PA, USA, 2019. 
109. Xue, D.-D.; Cheng, Y.; Wu, M.; Zhang, Y. Comprehensive geriatric assessment prediction of postoperative complications in gastrointestinal cancer patients: A meta-analysis. Clin. Interv. Aging 2018, 13, 723-736. [CrossRef] [PubMed]

110. Maekawa, Y.; Sugimoto, K.; Yamasaki, M.; Takeya, Y.; Yamamoto, K.; Ohishi, M.; Ogihara, T.; Shintani, A.; Doki, Y.; Mori, M.; et al. Comprehensive Geriatric Assessment is a useful predictive tool for postoperative delirium after gastrointestinal surgery in old-old adults. Geriatr. Gerontol. Int. 2016, 16, 1036-1042. [CrossRef] [PubMed]

111. Mason, M.C.; Crees, A.L.; Dean, M.R.; Bashir, N. Establishing a proactive geriatrician led comprehensive geriatric assessment in older emergency surgery patients: Outcomes of a pilot study. Int. J. Clin. Pr. 2018, 72, e13096. [CrossRef] [PubMed]

112. Ghignone, F.; Van Leeuwen, B.; Montroni, I.; Huisman, M.; Somasundar, P.; Cheung, K.; Audisio, R.; Ugolini, G. The assessment and management of older cancer patients: A SIOG surgical task force survey on surgeons' attitudes. Eur. J. Surg. Oncol. (EJSO) 2016, 42, 297-302. [CrossRef]

113. To, T.H.M.; Soo, W.K.; Lane, H.; Khattak, A.; Steer, C.; Devitt, B.; Dhillon, H.M.; Booms, A.; Phillips, J. Utilization of geriatric assessment in oncology-A survey of Australian medical oncologists. J. Geriatr. Oncol. 2019, 10, 216-221. [CrossRef]

114. Koneru, R.; Freedman, O.; Lemonde, M.; Froese, J. Evaluation of a comprehensive geriatric assessment tool in geriatric cancer patients undergoing adjuvant chemotherapy: A pilot study. Support. Care Cancer 2019, 27, 1871-1877. [CrossRef]

115. Kagan, E.; Freud, T.; Punchik, B.; Barzak, A.; Peleg, R.; Press, Y.A. Comparative Study of Models of Geriatric Assessment and the Implementation of Recommendations by Primary Care Physicians. Rejuvenation Res. 2017, 20, 278-285. [CrossRef]

(C) 2019 by the authors. Licensee MDPI, Basel, Switzerland. This article is an open access article distributed under the terms and conditions of the Creative Commons Attribution (CC BY) license (http://creativecommons.org/licenses/by/4.0/). 